\title{
Review
}

Medical Principles
and Practice

\section{Managing Palliative Care at Home}

\author{
Julia Hannan \\ Great Ormond Street Hospital, London, UK
}

\section{Key Words}

Palliative care - Paediatric care

\begin{abstract}
This paper outlines the principles of palliative care (PC) provision for sick children at home, in the UK. The differences between home and hospital with regard to the illness and availability and type of services and equipment are discussed. The need to plan for the availability of appropriate professional staff, equipment, medication, information and the procedure when the child dies is discussed. Successful PC at home is possible for most children, if plans are made for all potential eventualities. These principles of PC may be helpful in delivering PC at home in other countries.
\end{abstract}

Copyright $\odot 2007$ S. Karger AG, Basel

\section{Introduction}

Many families with children suffering from cancer spend much time in hospital, and, often when they are told that their child's disease has relapsed and that nothing more can be done, their first wish is to care for their child at home. Palliative care (PC) in the home presents challenges for health professionals as well as families. This paper examines the principles applicable to providing PC for children at home in the UK. Services and legislation differ in each country regarding what is possible to be provided at home. Hopefully, the basic principles outlined here can be adapted and applied to services in other countries.

\section{KARGER \\ Fax +4161306 1234 \\ E-Mail karger@karger.ch}

www.karger.com

\section{Why Home?}

Research in the 1950s and 1960s demonstrated that hospitalisation can have detrimental effects on children's well-being $[1,2]$. Paediatric services in the UK have been developed to make hospitals more family friendly and whenever possible to enable PC delivered at home or on an outpatient basis. It has been well documented in the UK and USA that children and families prefer PC to be delivered at home whenever possible [3-5]. This gives the families a sense of normality and a more relaxed atmosphere and control over their child's care so that many family and sibling activities can continue, with favourite toys being at hand and extended family and friends visiting more easily $[3,4,6,7]$.

\section{What Is Different about Home Care?}

Most symptoms are managed in the same way, using the same drugs at home as in hospital. However, there are differences when providing PC at home with regard to the situation and availability of services and equipment.

\section{Situation}

The philosophy that underpins paediatric care, that of family-centred negotiated care, is of paramount importance when providing care in a family's home [8]. Martinson et al. [9] described how roles change when care is given at home, as parents become the primary caregivers and doctors and nurses take on consultancy and facilitator roles, becoming guests in the family's home. As primary caregivers, parents take the responsibility for ad-

\footnotetext{
Julia Hannan

Clinical Nurse Specialist, Symptom Care Team

Great Ormond Street Hospital

London WC1N 3JH (UK)

E-Mail HannaJ@gosh.nhs.uk
} 
ministration of medications and often other interventions such as nasogastric feeding and suction, if required. Before a family takes their child home, staff must spend time teaching the parents any skills required to care for their child [10]. There should be anticipation of any future skills that may be needed as their child's condition deteriorates. This is particularly important since the child receiving care is at home and although health care professionals may be able to visit the family, they are not on hand $24 \mathrm{~h}$ a day, as in hospital.

\section{Availability and Type of Services}

Generally a smaller, more consistent team of professionals provide care for families at home. This is advantageous in reducing communication problems regarding plans for treatment that can occur when patients are in hospital care where they are cared for by many different shifts of nursing and medical staff. However, a main disadvantage with caregiving in the home is that services may only be available during office or daytime hours. Studies have shown that families find night-time quite frightening at home [4] and value having someone to contact and discuss problems with, $24 \mathrm{~h}$ a day, 7 days a week [11]. Our experience shows that if 24 -hour care is to be offered, it should be offered in a structured way, with a team sharing the responsibility. If one person takes on the responsibility, this individual soon becomes exhausted and the service fails. If it is not possible to offer 24-hour cover, the family should be aware of this and prior information should be given about receiving assistance.

The key staff providing PC for children dying from cancer in the home in the UK are paediatric oncology outreach nursing teams, children's community nurses, general practitioners and sometimes local paediatricians and social workers. As providers of specialist PC, it is important to consider the type and amount of support that professionals require to give for day-to-day care [3]. Some individuals and teams providing care locally may have much experience of caring for dying children and their families, but for others the experience may be very new. Ideally, all members of the care team should collaborate to ensure guidance and support needed is provided with regard not only to symptom management, but also to wider issues about caring for a dying child at home without duplicating efforts.

\section{Availability and Type of Equipment}

Many pieces of equipment used in hospital are simply too big to be used successfully at home; however, smaller and more portable devices specifically designed for home use are available. Parameters such as oxygen saturations are regularly monitored in hospital, but it will not be possible or appropriate to continue monitoring at home. In these situations, families must be aware of the level of monitoring that is possible and agreement should be reached between the family and the health care staff about what is appropriate or not. The time between ordering an item of equipment and its delivery should also be ascertained as part of the plan to provide care for children at home. The health care teams need to know who will provide, fund and deliver equipment. Should the original item break down, backup equipment should be available, but this is not always possible. Consideration should also be given for replenishment, collection and disposal of single-use items and clinical waste such as sharp bins.

\section{Planning Ahead}

The key to successful PC at home is planning at least one step ahead for all eventualities that may arise.

\section{Personnel}

Various specialist care team members should collaborate to provide help specific in their area of expertise and parents should have appropriate contact information, but they often prefer a key worker who may be contacted [12, 13]. The key worker can be any of the professionals involved in each child's care, and may vary for each family $[12,13]$. Clear plans should be made regarding care out of working hours.

\section{Equipment}

Equipment for home care requires assessment of the child's current needs. Nursing aids such as nasogastric feeding pumps, commode with appropriate height or beanbag or sofa, disposable items such as feeding sets as well as a smaller, more portable pump makes caring in the home easier and enables the family to make the most of their time with their child.

With disease progression, it is important to plan ahead for provision and delivery of equipment, such as wheelchair or buggies to enable mobility outside the home. A syringe driver may be required if medication cannot be delivered in any other way in the last stages of illness.

\section{Medication}

Planning ahead is particularly important with regard to medication management, especially if there are difficulties around the supply of some types of medication 
(for example diamorphine or other controlled drugs). As families will be administering medications, they need to be given clearly written instructions about symptom-specific medication and the quantity to be given. A common error in administering medication is a misunderstanding with decimal point position ( $2 \mathrm{ml}$ of a drug instead of 0.2 $\mathrm{ml})$. Allocating one syringe per medication, marked at the required dose, would eliminate such an error. Upon dose changes, the syringe should also be remarked. Sufficient stock should be available to allow for increases in treatment, and amounts required for weekends and holiday periods. All those involved, including family members, should be able to check for supplies of medication running out and know how to obtain replenishments. A system should be in place to enable easy access to supplies as needed.

Medication for management of anticipated symptoms should be planned. Such drugs, if the family agrees, should be stored at hand in the sick child's home. If not, these should be stored where 24-hour access is available. Alternative routes of administration (rectal, subcutaneous, intravenous, buccal and epidural) should also be discussed with the family for when the preferred oral route is no longer suitable due to coma or absorption problems. Some routes may limit the medications that can be used at home, for example, an epidural route may only be possible if the child is in a hospital or a hospice. Depending on the availability of health care staff and the willingness of the family, it may be necessary or desirable to train the family members to make up syringes to administer medications via a subcutaneous driver [10].

\section{Information}

It is important to ensure that families have the information needed to plan for their child's care. An appropriate amount of information to get through the day or a full history should be given according to the wishes of the family. It is important to ascertain with each family regarding the amount of information they wish to know in advance of events occurring, how they would prefer to receive that information and who should receive it. Information regarding the child's safety should be given, for example, for a child at risk of seizures and appropriate measures to control the fit should be taken. It is imperative to give appropriate information, or else caring for the child can be made more difficult and frightening $[11,14$, 15].

Palliative Home Care
It is also important to remember that siblings can feel excluded and frightened if they do not understand what is happening to their sick brother or sister. Studies $[12,14]$ have shown that being sensitive but honest with children about the illness and potential loss enables them to cope. To this end, child specialists, also known as play specialists, can assist in exploring concerns of the children and explain complex situations to them. The concerns of extended family also need to be addressed, but the amount of information to be provided must only be given with the consent of parents.

Families should be made aware of the changes, such as cachexia or Cushing's syndrome (if a child is on steroids) that they will see in their child's appearance as the disease progresses. They ought to be informed of changes that they would see in the child's behaviour and routine - eating and playing less, sleeping longer and also during the day.

A subject many families worry about but at times are too afraid to ask is recognising that the time of death is approaching. This should be discussed with the families, describing changes in the level of consciousness and breathing pattern (Cheyne-Stoke breathing), which indicate that the end of the child's life is approaching. Such a discussion allays some fears and instils confidence into the family that they can cope with caring at home [3].

Hannan and Gibson [11] found that when families first hear that their child's disease is incurable, their focus is on where to spend the time that their child has left to live, not on where they want their child to die. The desire to care for their child at home may not necessarily be that of the sick child, thus, open communication, flexibility in care, and a plan for an alternative place of care that respects the wishes of the whole family should be available.

\section{When the Child Dies}

The family that cares for their child at home should also be aware of the procedures to be followed when the child dies. Questions and procedures need to be addressed: selecting whom the family would like to be with at this time, whom to call after the child has died, whether they would like to call people themselves or they would like someone else to call. If a child and family are from a different culture or religion than that of the professionals, the latter should be aware of appropriate behaviour upon death according to cultural and religious customs of the sick child.

Med Princ Pract 2007;16(suppl 1):33-36 


\section{Conclusion}

Providing care at home can be an option for most families. Families need to be aware of their options regarding their child's care. The place of care and place of death may be different. Home caregivers need clear information re- garding expected symptoms, medication, dosage and usage, and clear contact details for professional help. Care providers require detailed planning for all eventualities as far ahead as possible, and need to be flexible to respond to new situations.

\section{References}

1 Bowlby J: Child Care and the Growth of Love. Harmondsworth, Penguin, 1953.

2 Robertson J: Young Children in Hospital, ed 2. London, Tavistock Publications, 1970.

$\checkmark 3$ Goldman A, Beardsmore S, Hunt J: Palliative care for children with cancer - Home, hospital or hospice? Arch Dis Child 1990;65:641643.

4 Vickers J, Carlisle C: Choices and control: parental experiences in paediatric terminal home care. J Pediatr Oncol Nurs 2000;17:1221.

5 Hynson JL, Sawyer SM: Paediatric palliative care: distinctive needs and emerging issues. J Paediatr Child Health 2001;37:323-325.

-6 Papadatou D, Yeantoupoulos J, Kosmidis KV: Death of a child at home or in hospital: experiences of Greek mothers. Death Stud 1996;20:215-235.
Davies B, Deveau E, de Veber B, Howell D, Martinson I, Papadatou D, Pask E, Stevens $\mathrm{M}$ : Experiences of mothers in five countries whose child died of cancer. Cancer Nurs 1998;21:301-311.

8 Casey A: A partnership with child and family. Sr Nurse 1988;8:8-9.

-9 Martinson IM, Moldow DG, Armstrong GD, Henry WF, Nesbit ME, Kersey JH: Home care for children dying of cancer. Res Nurs Health 1986;9:11-16.

10 Darbyshire P, Haller A, Fleming SL: The Interstellar Cold: Parents' Experiences of Their Child's Palliative Care. A Report Prepared for the South Australian Health Commission, Palliative Care Program - Statewide Projects. Adelaide, South Australian Health Commission, 1997.

11 Hannan J, Gibson F: Advanced cancer in children: how parents decide on final place of care for their dying child. Int J Palliat Nurs 2005;11:284-291.
12 Association for Children with Life-Threatening or Terminal Conditions and Their Families (ACT) and The Royal College of Paediatrics and Child Health (RCPCH): A Guide to the Development of Children's Palliative Care Services. London, ACT and RCPCH, 2003.

13 National Institute for Health and Clinical Excellence: Guidance on Cancer Services: Improving Outcomes in Children and Young People with Cancer. London, National Institute for Health and Clinical Excellence, 2005.

14 Dufour D: Home or hospital care for the child with end-stage cancer: effects on the family. Issues Compr Pediatr Nurs 1989;12: 371-383.

15 James L, Johnson B: The needs of parents of pediatric oncology patients during the palliative care phase. J Pediatr Oncol Nurs 1997; 14:83-95. 